\title{
Caracteres morfofisiológicos e produtividade da soja em razão da desfolha no estádio vegetativo
}

\section{Morphophysiological characters and soybean yield due to defoliation at vegetative stage}

\author{
Velci Queiróz de SOUZA'; Maicon NARDINO ${ }^{2}$; Diego Nicolau FOLLMANN ${ }^{3}$; \\ Carlos André BAHRY ${ }^{4}$; Braulio Otomar CARON ${ }^{1}$; Paulo Dejalma ZIMMER ${ }^{5}$ \\ ${ }^{1}$ Professor Dr. Universidade Federal de Santa Maria, Campus de Frederico Westphalen. velciq@gmail.com \\ otomarcaron@yahoo.com.br \\ ${ }^{2}$ Autor para correspondência. Doutorando do Programa de Pós Graduação em Agronomia, Centro de Genômica \\ e Fitomelhoramento da Universidade Federal de Pelotas. nardinomn@gmail.com \\ ${ }^{3}$ Mestrando do Programa de Pós Graduação em Agronomia, Agricultura e Ambiente, Universidade Federal de \\ Santa Maria, Campus de Frederico Westphalen. diegonicolaufollmann@gmail.com \\ ${ }^{4}$ Doutorando do Programa em Ciência e Tecnologia de Sementes, Universidade Federal de Pelotas. \\ carlosbahry@hotmail.com \\ ${ }^{5}$ Professor Dr. Universidade Federal de Pelotas. dejalma@msn.com
}

Recebido em: 03-02-2014; Aceito em: 15-04-2014

\section{Resumo}

O objetivo do trabalho foi avaliar o efeito da desfolha artificial nos estádios vegetativos sobre 0 número de estruturas reprodutivas na soja, e por consequência, o rendimento de grãos. Este estudo foi conduzido na área experimental da UFSM, Câmpus de Frederico Westphalen-RS, na safra de 2010/2011. A cultivar de soja Roos Camino RR foi submetida aos seguintes tratamentos de desfolha: T1: sem desfolha; T2: remoção do par de folhas unifolioladas no estádio fenológico V4; T3: T2 + remoção do $1^{\circ}$ trifólio em V5; T4: T3 + remoção do $2^{\circ}$ trifólio em V6; T5: T4 + remoção do $3^{\circ}$ trifólio em V7; T6: T5 + remoção do $4^{\circ}$ trifólio em V8; T7: T6 + remoção do $5^{\circ}$ trifólio em V9. As variáveis analisadas foram: índice de clorofila das folhas (mensurado nos terços superior, médio e inferior das plantas), nos estádios vegetativos V4, V5, V6, V7, V8 e V9; número de flores na floração plena; número de legumes no estádio R4; e legumes totais em R8. Foi efetuada análise de variância e, na presença de efeitos significativos para a interação, os fatores de tratamentos foram desmembrados aos efeitos simples; na ausência de significância, desmembraram-se os efeitos principais. $O$ índice de clorofila não é afetado pela desfolha. O desfolhamento nos estádios vegetativos reduz o número de flores, porém tais reduções são compensadas pela menor abscisão de flores remanescentes e maior fixação de legumes. Os níveis de desfolhamento não influenciam no número de legumes totais e no rendimento de grãos da soja.

Palavras-chave adicionais: desfolhamento; florescimento; Glycine Max; índice de clorofila.

\begin{abstract}
The aim of this study was to evaluate the artificial defoliation effect in vegetative stages on the number of soybean reproductive structures and consequently, the grain yield. This study was conducted in the UFSM experimental area, Campus Frederico Westphalen, the 2010/2011 harvest. The soybean cultivar Roos Camino RR was subjected to the following defoliation treatments: T1: without defoliation, T2: removal of the unifoliolate leaves pair in V4 growth stage, T3: T2 + removal 1st trefoil in V5 growth stage, T4: T3 + removal of the 2nd trefoil in V6 growth stage, T5: T4 + removal of the 3rd trifoliate in V7 growth stage; T6:T5 + removal in the 4th trifoliate in V8 growth stage, T7: T6 + removal 5th trifoliate in V9 growth stage. The variables analyzed were : leaves chlorophyll index (measured in the upper, middle and lower thirds of plants), in V4, V5 , V6 , V7 , V8 and V9 vegetative stages, number of flowers in full bloom, pods number in R4 growth stage, and total pods in R8 growth stage. Variance analysis was performed and, in the presence of significant interaction effects, the treatments factors to simple effects were dismembered; in the absence of significant, the principal effects were dismembered. The chlorophyll index is not affected by defoliation. The defoliation in the vegetative stages reduces the of flower numbers, but such reductions are compensated by lower abscission of remaining flowers and the largest pods fixation. Defoliation levels do not influence the total number of pods and soybean grain yield.
\end{abstract}

Additional keywords: chlorophyll index; defoliation; flowering; Glycine max. 


\section{Introdução}

A habilidade da soja em evitar variações de produtividade após sofrer desfolha precoce, ocasionada, principalmente, pelo ataque de insetos-praga, doenças como a ferrugem-asiática e granizo, está na dependência de vários fatores, dentre os quais a intensidade do desfolhamento, o estádio de desenvolvimento fenológico na ocasião da desfolha, a habilidade da cultivar em tolerar ou compensar o desfoIhamento, fatores ambientais como volume e regularidade de precipitação pluvial, temperatura e radiação solar (PARCIANELLO et al., 2004).

No caso em particular do ataque de insetos-praga, a maioria das recomendações para seu controle segue os níveis da década de 70 , em que o mesmo está baseado em $30 \%$ de desfolha na fase vegetativa e $15 \%$ na fase reprodutiva e, ainda, em sua maioria, em cultivares de hábito de crescimento determinado, com baixos potenciais genéticos de produtividade (PARCIANELLO et al., 2004). No entanto, a realidade das novas cultivares é outra, quando comparada às cultivares antigas, sendo aquelas mais produtivas, com hábito de crescimento indeterminado (em sua maioria), arquitetura de planta mais compacta com folhas mais eretas e lanceoladas e ciclos mais curtos, necessitando-se, em virtude disso, de novas informações para se estimar danos econômicos atribuídos à desfolha.

Em trabalho conduzido por BAHRY et al. (2013), foi observado que, em lavouras com alto potencial produtivo, acima de 60 sacos de soja por hectare e com emprego de alta tecnologia e condições climáticas favoráveis, a desfolha em diferentes níveis pode comprometer a produtividade, e à medida que se elevavam os níveis de desfolha na fase vegetativa da soja, a produtividade era reduzida, até um limite de sete sacos de soja por hectare no maior nível de desfolha. Porém, em condições de baixa produtividade, com clima desfavorável, a desfolha deixa de ser o fator limitante em maior grau, não comprometendo a produtividade da soja. Desta forma, qualquer fator que venha a modificar a arquitetura do dossel das plantas na lavoura pode ocasionar redução da área foliar efetiva, diminuindo a intercepção da luz, a taxa de crescimento da cultura (TCC), o acúmulo de massa seca (MS) e, consequentemente, podendo levar a um decréscimo do rendimento de grãos (HAILE et al., 1998). Diversas pesquisas foram realizadas, variando épocas (desde estádios vegetativos iniciais até reprodutivos finais) e níveis (de 0 a 100\%) de desfolhamento, demonstrando desde a não ocorrência de resposta até $87 \%$ de redução no rendimento (RIBEIRO \& COSTA, 2000; BAHRY et al., 2013), não corroborado por BAHRY et al. (2013), em lavouras de soja de alto desempenho.

Para PEREIRA (2002), o aumento na taxa fotossintética dos estádios vegetativos aos reprodutivos ocorre através do incremento da fotossíntese no momento de aumento da demanda por fotoassimilados, principalmente na formação e no desenvolvimento dos legumes. É evidente, portanto, que a integridade da parte aérea nestes estádios de desenvolvimento, em que qualquer fator que interfira negativamente em sua área foliar afetará a produtividade final. Tem-se verificado que a desfoIha inferior a 50\%, antes do florescimento, usualmente não reduz o rendimento de grãos, enquanto acima desse nível, durante os estádios reprodutivos, tem causado maiores reduções na produtividade (DIOGO et al., 1997). Entretanto, CAVINESS \& THOMAS (1980) observaram menor produtividade com desfolhas efetuadas nos estádios vegetativos V3 e V5 em comparação à obtida com desfolhas na floração plena e no desenvolvimento dos legumes.

O objetivo do trabalho foi avaliar o efeito da desfolha artificial em diferentes estádios vegetativos sobre o número de estruturas reprodutivas nas plantas de soja e, por consequência, no rendimento final de grãos.

\section{Material e métodos}

O presente trabalho foi conduzido na área experimental da Universidade Federal de Santa Maria, no Câmpus de Frederico Westphalen-RS, em solo classificado como Latossolo Vermelho-Alumino-Férrico. O clima, conforme classificação de Köppen, é do tipo Cfa, subtropical, tendo o local, como coordenadas geográficas, $27^{\circ} 39^{\prime} 56^{\prime \prime} \mathrm{S}$ de latitude e $53^{\circ}$ 42' 94" O de longitude e altitude de 490 metros.

Para o experimento, foi utilizada a cultivar de soja Roos Camino RR que apresenta como características hábito de crescimento indeterminado e alto potencial produtivo. $\mathrm{O}$ delineamento experimental utilizado foi o de blocos ao acaso, com sete tratamentos e quatro repetições, totalizando 28 unidades experimentais. Cada parcela foi dimensionada em quatro linhas de semeadura, com três metros de comprimento, espaçadas em 0,45 m. A metodologia adotada neste experimento consta na Tabela 1. 
Tabela 1 - Tratamentos de desfolha artificial em diferentes estádios vegetativos sobre a cultivar de soja Roos Camino RR e estimativa do nível de desfolha ocasionado.

\begin{tabular}{ccc}
\hline Tratamento & \multicolumn{1}{c}{ Descrição } & Nível de desfolha* $(\%)$ \\
\hline T1 & Sem desfolha artificial & 0 \\
T2 & Remoção do par de folhas unifolioladas em V4 & 25 \\
T3 & T2 + remoção do 10 trifólio em V5 & 40 \\
T4 & T3 + remoção do 20 trifólio em V6 & 50 \\
T5 & T4 + remoção do 30 trifólio em V7 & 57 \\
T6 & T5 + remoção do 40 trifólio em V8 & 62,5 \\
T7 & T6 + remoção do 50 trifólio em V9 & 66,7 \\
\hline
\end{tabular}

*referente ao percentual de nós vegetativos que foram mantidos sem folhas em cada tratamento ${ }^{* *}$ escala fenológica de Fehr e Caviness (1977)

As variáveis analisadas foram:

Índice de clorofila: obtido com auxílio de clorofilômetro digital, modelo SPAD 502, sendo o valor de clorofila obtido nos estádios vegetativos V3, V4, V5, V6, V7 e V8, de acordo com a escala fenológica de FEHR \& CAVINESS (1977), em três plantas marcadas nas linhas centrais de cada unidade experimental, com leituras nos terços superior, médio e inferior de cada planta. Esta etapa precedeu cada aplicação de desfolha, respeitando-se os níveis de cada tratamento da Tabela 1. Realizaram-se três leituras em cada folha, da base do limbo até a extremidade distal da folha, computando a média por folha em cada terço da planta. Em seguida, somaram-se os valores obtidos das três plantas na repetição, fazendose uma média geral do tratamento no bloco. Para adequação dos índices de clorofila na folha, foi estabelecida a equação, em $\mathrm{mg} \mathrm{L}^{-1}$ :

$\mathrm{TC}=-1.4693+0,3975 \mathrm{~S}$

em que TC equivale ao teor de clorofila e " $S$ " ao valor SPAD (MORAN \& PORATH, 1980).

O horário de avaliação foi padronizado para as dez horas da manhã.

Número de flores por planta: contagem realizada após a marcação aleatória de três plantas na unidade experimental, realizando-se a mensuração no estádio de florescimento pleno (R2), de acordo com escala de FEHR \& CAVINESS (1977).

Número de legumes em formação: determinado por meio da contagem do número de legumes por planta quando esta se encontrava no estádio fenológico R4, caracterizada pela formação completa dos legumes, porém sem granação visível.

Número de legumes formados: contagem simples do número de legumes por planta no estádio fenológico R8, de acordo com a escala de FEHR \& CAVINESS (1977), tendo $100 \%$ de granação.

Produtividade de grãos: obtida pela massa total de grãos de cada repetição, corrigido para $12 \%$ de umidade, extrapolando o resultado para kg ha ${ }^{-1}$.

Tendo conhecimento da influência do clima sobre a cultura, os dados climatológicos foram compilados durante o desenvolvimento da cultura para melhor entendimento dos resultados. As variáveis meteorológicas avaliadas foram: temperatura do ar máxima e mínima, acúmulo de radiação solar global durante os estádios fenológicos e o extrato do balanço hídrico do período de condução do ensaio.

Os dados meteorológicos foram obtidos junto à estação meteorológica do INMET, localizada na Universidade Federal de Santa Maria Câmpus Frederico Westphalen, distante, aproximadamente, a 200 metros do local do experimento.

Os resultados obtidos foram submetidos à análise de variância, pelo teste $\mathrm{F}$. Revelando efeitos significativos para interação, passaram-se aos desmembramentos dos efeitos simples, e na ausência de interação, passaram-se aos desmembramentos dos efeitos principais, sendo as médias comparadas pelo teste de Tukey, a $5 \%$ de probabilidade.

\section{Resultados e discussão}

Observaram-se efeitos significativos para a interação entre tratamentos de desfolha e estádios fenológicos em que se avaliou o índice de clorofila nos terços superior e inferior das plantas e efeitos significativos para o número de flores, legumes em formação e legumes totais.

Desmembrando os efeitos simples do caráter índice de clorofila no terço superior, observa-se que, para os tratamentos 1, 2 e 7 (Tabela 1), não houve diferenças significativas entre os estádios, ressaltando-se a igualdade do tratamento 1 , sem desfolha, com o tratamento 7 , nível máximo de desfolha. Para o tratamento 3 , na avaliação do teor de clorofila, o estádio V5 revela menor valor. Os tratamentos 4,5 e 6 revelam maior índice de clorofila em V5 e V7 (Tabela 2).

Com relação à comparação do índice de clorofila, dentro de cada estádio fenológico, revelam-se resultados similares para a testemunha e o tratamento 6 , exceto para a leitura realizada no estádio vegetativo V5. O tratamento 7 , com $66,7 \%$ de desfolha, não difere da testemunha nos teores 
de clorofila avaliados nos estádios V6 e V8, no terço superior da planta. A ausência de alteração no índice de clorofila, em função da aplicação de desfolha, pode ser explicada pelo trabalho desenvolvido por THORNE \& KOLLER (1974). Os autores cobriram por completo plantas de soja, por um período de oito dias, com exceção de uma única folha. Como resultado, muitas mudanças ocorreram na folha-fonte remanescente, como o decréscimo de amido, aumento da taxa fotossintética e da atividade da rubisco, maior concentração de sacarose, maior transporte de sacarose e aumento na concentração de ortofosfato. Ou seja, essa folha tornou-se muito mais eficiente.

Tabela 2 - Teores de clorofila, em $\mathrm{mg} \mathrm{L}^{-1}$, nos estádios V5, V6, V7 e V8, no terço superior, terço inferior e terço médio da planta.

\begin{tabular}{|c|c|c|c|c|}
\hline \multirow{2}{*}{ Tratamentos } & \multicolumn{4}{|c|}{ Teor no terço superior } \\
\hline & V5 & V6 & V7 & V8 \\
\hline 1 & $13,54 \mathrm{~b} \mathrm{~A}$ & 13,55 a $A$ & $13,82 a b A$ & 13,63 a $A$ \\
\hline 2 & $13,94 \mathrm{ab} A$ & $13,11 a b c A$ & $13,94 a b \mathrm{~A}$ & 13,46 a $A$ \\
\hline 3 & 12,17 c B & $13,21 a b c A$ & $13,45 a b A$ & 13,50 a $A$ \\
\hline 4 & $13,62 a b A B$ & 12,66 bc $C$ & 14,12 a $A$ & $13,14 a b B C$ \\
\hline 5 & $14,04 \mathrm{ab} A$ & $12,51 \mathrm{c} \mathrm{B}$ & $13,59 a b A$ & 12,56 b B \\
\hline 6 & 14,46 a $A$ & $13,51 \mathrm{ab} B$ & $13,97 a b A B$ & $13,28 \mathrm{ab} B$ \\
\hline 7 & 13,28 b A & $13,08 a b c A$ & $13,17 \mathrm{~b} \mathrm{~A}$ & $12,87 \mathrm{ab} A$ \\
\hline \multirow[t]{2}{*}{ CV (\%) } & \multicolumn{4}{|c|}{6,65} \\
\hline & \multicolumn{4}{|c|}{ Teor no terço inferior } \\
\hline 1 & 16,13 a $A$ & 15,27 a $B$ & $16,02 \mathrm{ab} A B$ & 16,02 a $A B$ \\
\hline 2 & $16,02 \mathrm{ab} A$ & 15,64 a $A$ & 16,07 a $A$ & 15,92 a $A$ \\
\hline 3 & 14,57 b B & 15,40 a $A$ & $15,22 \mathrm{~b} A B$ & 15,86 a $A$ \\
\hline 4 & $15,34 \mathrm{ab} A$ & 15,46 a $A$ & $15,57 \mathrm{ab} A$ & 16,14 a $A$ \\
\hline 5 & $15,32 \mathrm{ab} A$ & 15,32 a $A$ & $15,70 \mathrm{ab} A$ & 15,74 a $A$ \\
\hline 6 & 15,22 b A & 15,13 a $A$ & $15,74 \mathrm{ab} A$ & 15,35 a $A$ \\
\hline 7 & $15,85 a b A B$ & 15,14 a B & 16,10 a $A$ & 15,79 a $A B$ \\
\hline \multirow[t]{2}{*}{ CV (\%) } & \multicolumn{4}{|c|}{5,28} \\
\hline & \multicolumn{4}{|c|}{ Teor no terço médio } \\
\hline 1 & \multicolumn{4}{|c|}{$14,83 \mathrm{a}$} \\
\hline 2 & \multicolumn{4}{|c|}{$14,78 a b$} \\
\hline 3 & \multicolumn{4}{|c|}{$14,18 \mathrm{c}$} \\
\hline 4 & \multicolumn{4}{|c|}{$14,51 \mathrm{abc}$} \\
\hline 5 & \multicolumn{4}{|c|}{$14,39 \mathrm{bc}$} \\
\hline 6 & \multicolumn{4}{|c|}{$14,63 a b$} \\
\hline 7 & \multicolumn{4}{|c|}{$14,43 \mathrm{abc}$} \\
\hline CV (\%) & \multicolumn{4}{|c|}{6,51} \\
\hline
\end{tabular}

Médias seguidas pela mesma letra minúscula na coluna e maiúsculas na linha não diferem pelo teste de Tukey, a 5\% de probabilidade de erro.

Essas mudanças, no entanto, não podem ser percebidas pelo índice de clorofila. Logo, apesar de sua semelhança entre os tratamentos de desfolha e a testemunha, não significa que as folhas remanescentes não encontraram outras formas de amenizar o impacto da ausência de folhas, corroborando essa possível explicação com os dados de produtividade (Tabela 3). Esse estudo indica que, além das alterações de curto prazo na distribuição de fotoassimilados entre os diferentes drenos (raízes, nódulos, folhas em expansão, grãos), o metabolismo da fonte ajusta-se às condições alteradas em experimentos de longa duração.

Apesar de o experimento realizado por THORNE \& KOLLER (1974) envolver o recobri- mento de folhas, o mesmo pode ser, dadas as proporções, extrapolado para trabalhos de desfoIha, visto que o metabolismo de ambas as folhas é cessado ou bastante reduzido, com a queda, ou com a falta de luz, respectivamente. Isso revela a importância da pesquisa no assunto para rever os níveis de desfolha tolerados pelas plantas de soja como medida de entrada na lavoura para combater pragas desfolhadoras. Os níveis, hoje, são fixados em $30 \%$ na fase vegetativa da soja; contudo, cada cultivo tem suas particularidades, e esses níveis deveriam ser revistos, com base nas cultivares modernas de soja presentes no mercado, que apresentam comportamentos distintos entre si e também são muito mais eficientes na utilização de recursos, podendo, em determinadas 
situações, aceitar níveis superiores de desfolha sem justificar o controle de algum fator biótico, como no caso de insetos desfolhadores, o que está diretamente relacionado com o custo de produção, tendo impacto direto na economia. E, considerando a grande entrada no mercado de cultivares com hábito de crescimento indeterminado, a ampliação dessa linha de pesquisa deveria ser mais pronunciada.

Esse raciocínio vem ao encontro da filosofia do manejo integrado de pragas, que se baseia na premissa de que não são todas as espécies de insetos que necessitam de controle e que alguns níveis de infestação e injúria são toleráveis pelas plantas, sem redução econômica da produção final (BUENO et al., 2010).

NOGUEIRA et al. (2010) destacam que as leituras do clorofilômetro fornecem um indicativo do desenvolvimento vegetativo e da produtividade da cultura da soja, destacando que níveis elevados são importantes para manutenção e enchimento de grãos ou acúmulo de reservas. Com relação ao índice de clorofila no terço inferior (Tabela 2), abordando inicialmente os níveis de desfolha dentro de cada estádio fenológico, a testemunha revela-se superior aos tratamentos 3 e 6, com níveis de desfolha de 40 e 62,5\%, respectivamente, no estádio vegetativo V5. O índice de clorofila não foi influenciado pelos níveis de desfolhamento em V6 e V8. Na análise de clorofila em V7, os tratamentos 7 e 2, com níveis de desfolha de 66,7 e $25 \%$, respectivamente, apresentaram maior valor em relação ao tratamento 3 , com $40 \%$ de desfolha. Na comparação do índice de clorofila entre os estádios para o mesmo nível de desfolha, a testemunha, no estádio V5, revela maiores índices de clorofila em comparação ao estádio V6. Na análise do tratamento 3, os índices revelados em V6 e V8 são superiores ao teor de clorofila observado em V5. Em relação ao tratamento 7 (Tabela 2), o maior valor de clorofila foi observado no estádio V7, quando comparado aos demais, seguido de V6, e não havendo diferença entre os demais tratamentos de desfolha quanto ao índice de clorofila.

No terço médio das plantas (Tabela 2), observam-se diferenças significativas entre os níveis de desfolhamento, em que a testemunha revela superioridade para o índice de clorofila em relação aos demais níveis de desfolha. $\mathrm{Na}$ fase vegetativa, as folhas de soja apresentam menor conteúdo de clorofila, aumentando gradativamente em razão das expansões da folha e pela demanda energética da planta, onde a ordem prioritária é determinada em função do estádio de desenvolvimento da cultura, sendo flores, legumes e grãos, órgãos prioritários na fase reprodutiva, e folhas, raízes e gemas vegetativas, no estádio vegetativo (JIANG et al., 2004).
Analisando o número de flores, nota-se que ocorreu diferença significativa em função dos níveis de desfolha (Tabela 3). O tratamento 1 (testemunha) apresenta o maior número de flores em comparação com os tratamentos 3, 4, 5,6 e 7, com níveis de desfolha de 40; 50; 57; 62,5 e $66,7 \%$, respectivamente. O menor número de flores é relacionado aos maiores níveis de desfolha, tratamentos 6 e 7, revelando que a desfolha artificial é um parâmetro que gera influência negativa sobre o número de flores na soja, devido à limitação da fonte. No entanto, a alta produção de flores não se traduz em maior produtividade final de grãos por planta (NAVARRO \& COSTA, 2002). Apenas 25 a $30 \%$ das flores produzem legumes, sendo esta característica dependente do vigor da planta no período de florescimento e da temperatura média no momento da formação dos legumes (FENDRICH, 2003).

As avaliações atribuídas ao número de legumes em formação, no estádio R4, que potencialmente virão a ser importantes contribuidores da produtividade final, podem ser constatadas pela Tabela 3. A testemunha, sem desfoIha, apresenta maior quantidade de legumes em formação, diferindo dos tratamentos com maiores níveis de desfolha. Desta maneira, pressupõe-se que o desfolhamento em níveis elevados durante a fase vegetativa pode reduzir o número de legumes potenciais, visto pelo menor número deste componente de rendimento nos tratamentos com maior desfolhamento.

Com relação ao número total de legumes formados no estádio R8 (Tabela 3), não foi possível observar diferença significativa entre os tratamentos de desfolha, não havendo efeito destes tratamentos na manutenção final deste componente de rendimento. Esse resultado vem ao encontro do observado por BAHRY et al. (2013), em que também não se observou efeito da desfolha no número de legumes. Porém, no referido trabalho, o número total deste componente por planta era bastante reduzido, devido à estiagem observada no local do experimento.

Passando à análise comparativa do número de legumes finais por planta em relação ao número de flores em R2, observam-se diferenças, em que os tratamentos com maiores níveis de desfolha (6 e 7), apresentaram gradativo aumento do número de legumes em comparação ao número de flores. Isso pode ser explicado pelo fato de que as cultivares modernas, de hábito de crescimento indeterminado, possuem a capacidade concomitante de produzir estruturas reprodutivas e vegetativas. Logo, após o florescimento pleno, novas estruturas reprodutivas podem vir a ser formadas. NAVARRO \& COSTA (2002), trabalhando com a expressão do potencial de rendimento de cultivares de soja, relatam que o alto potencial de rendimento 
não necessariamente identifica uma planta eficiente na retenção das estruturas reprodutivas, e os potenciais de rendimento estimados da floração e no enchimento de grãos não se mantêm até a maturação, característica que se observa no presente estudo, onde os tratamentos com maior número de estruturas reprodutivas não passaram a expressar maior rendimento de grãos, pressupondo-se que a abscisão de flores foi elevada para estes tratamentos.

Em pesquisa desenvolvida na seleção de genótipos de soja, SHARMA et al. (1990) relatam que é mais fácil a seleção de cultivares para um número menor de flores por nó, do que diminuir as taxas de abscisão floral, em função da herdabilidade que as plantas possuem em transferir tal característica para seus genótipos subsequentes. Baseado nisso, pode-se dizer que, havendo um número adequado de flores por racemo, seria mais benéfico para obtenção de grandes rendimentos. Logo, a alta produção de flores requer consumo de energia na planta. No entanto, em condições normais, grande parte sofre aborto, devido à relação fonte-dreno e capacidade da planta em suportar estruturas reprodutivas excedentes (THOMAS \& COSTA, 2010). Isso pode ser verificado no presente estudo, em que a testemunha, sem desfolha, teve maior número de flores, porém sem refletir em maior produtividade em relação aos demais tratamentos (Tabela 3).

Tabela 3 - Produção e fixação de flores em função dos tratamentos com desfolhamento. Frederico Westphalen, 2013.

\begin{tabular}{ccccc}
\hline Tratamentos & Estádio (R2) & Estádio (R4) & Estádio (R8) $)^{* *}$ & $\begin{array}{c}\text { Rendimento } \\
\left(\mathrm{kg} \mathrm{ha}^{-1}\right)\end{array}$ \\
\hline 1 & $54,00 \mathrm{a} \mathrm{A}^{*}$ & $46,08 \mathrm{a} \mathrm{B}$ & $40,75 \mathrm{a} \mathrm{B}$ & $3616,1 \mathrm{a}$ \\
2 & $46,83 \mathrm{ab} \mathrm{A}$ & $39,00 \mathrm{ab} \mathrm{B}$ & $37,00 \mathrm{a} \mathrm{AB}$ & $4108,8 \mathrm{a}$ \\
3 & $45,08 \mathrm{~b} \mathrm{~A}$ & $41,50 \mathrm{ab} \mathrm{A}$ & $45,62 \mathrm{a} \mathrm{A}$ & $3940,8 \mathrm{a}$ \\
4 & $42,25 \mathrm{~b} \mathrm{~A}$ & $39,42 \mathrm{ab} \mathrm{A}$ & $44,00 \mathrm{a} \mathrm{A}$ & $4310,9 \mathrm{a}$ \\
5 & $41,81 \mathrm{~b} \mathrm{~A}$ & $40,42 \mathrm{ab} \mathrm{A}$ & $42,00 \mathrm{a} \mathrm{A}$ & $3621,9 \mathrm{a}$ \\
6 & $32,00 \mathrm{c} \mathrm{B}$ & $34,58 \mathrm{~b} \mathrm{~A}$ & $44,12 \mathrm{a} \mathrm{A}$ & $3938,2 \mathrm{a}$ \\
7 & $26,83 \mathrm{c} \mathrm{B}$ & $35,83 \mathrm{~b} \mathrm{~A}$ & $46,12 \mathrm{a} \mathrm{A}$ & $4128,9 \mathrm{a}$ \\
\hline $\mathrm{CV}(\%)$ & 22,64 & & 9,94 \\
\hline
\end{tabular}

${ }^{*}$ Médias seguidas pela mesma letra minúscula na coluna e maiúsculas na linha não diferem pelo teste de Tukey, a $5 \%$ de probabilidade de erro. **Estádio reprodutivo R2 (Florescimento pleno); R4 (legumes formados sem granação); R8 (número total de legumes totais por planta na maturação fisiológica).

As flores que surgem nas diferentes posições do racemo não seguem a mesma tendência para abscisão. Segundo WIEBOLD (1990), as flores na posição distal do racemo são muito mais propensas à abscisão do que as flores da posição proximal. A probabilidade de abscisão de flores na posição proximal do racemo é frequentemente menor que $10 \%$; já nas estruturas encontradas na posição distal, é de $50 \%$ ou mais (WIEBOLD \& PANCEIRA, 1990).

$\mathrm{Na}$ comparação do número de flores que se tornaram legumes, verifica-se que 0 tratamento 1 , sem desfolha, é superior a todos os demais tratamentos, mas é constatado também que houve neste tratamento o maior índice de aborto de flores, juntamente com tratamento 2 ( $25 \%$ de desfolha) (Tabela 3 ). A competição entre as estruturas reprodutivas no racemo da soja, provavelmente, é a causa do início de abscisão da estrutura floral, aliado também à competição com 0 desenvolvimento vegetativo concomitante, visto ser uma cultivar de hábito indeterminado.

Os tratamentos com maior nível de desfolhamento acarretaram os menores índices de abortamento de flores, conferido através do número de legumes, com exceção dos tratamentos com maiores níveis de desfolha, tratamentos 6 e 7 (Tabela 3). Nestes, a taxa de abscisão floral foi inferior aos demais; possivelmente, o menor número de flores constatado em R2 gerou menor competição nos nós reprodutivos por assimilados, acarretando menor taxa de abscisão floral nas estruturas reprodutivas e maior fixação dos legumes que estavam em formação.

Nos estádios de formação dos legumes (R4 e R5), as plantas de soja demandam maior quantidade de energia para manter os legumes; também necessitam de fotoassimilados para desenvolvimento de novas estruturas reprodutivas. Esta condição fisiológica pode acarretar competição por assimilados dentro da planta, podendo diminuir o potencial de rendimento, gerando legumes com uma ou duas sementes, devido à não fecundação dos demais óvulos.

A menor produção de flores em R2 permite que a exigência por energia em R4 e R5 seja menor, potencializando a formação de legumes maiores e com maior número de grãos, 
ou diminuir a abscisão de flores e legumes em formação. Segundo NAVARRO JUNNIOR \& COSTA (2002), acredita-se que um menor número de flores pode tornar possível o aumento da produção de legumes com três grãos, tornando-se benéfico para produção final da planta. VENTIMIGLIA et al. (1999) destacam que, se todas as flores de soja presentes no estádio R2 gerassem legumes com grãos, a cultura teria um potencial de rendimento de $18 \mathrm{Mg} \mathrm{ha}^{-1} \mathrm{e}$, ainda, se todos os legumes presentes em R5 continuassem evoluindo até R8, o potencial de rendimento seria de $10 \mathrm{Mg} \mathrm{ha}^{-1}$; entretanto, os níveis de produtividade no trabalho alcançaram uma média final de $4,6 \mathrm{Mg} \mathrm{ha}^{-1}$.

Com relação ao rendimento de grãos (Tabela 3), revela-se ausência de diferença significativa entre os níveis de desfolhamento. Este resultado demonstra que os níveis de desfolha aplicados nos estádios vegetativos não são suficientes para comprometer a produtividade de grãos. A não significância da variável pode estar relacionada a fatores como as condições climáticas que transcorreram dentro da normalidade exigida pela cultura e também pela habilidade da cultivar de hábito de crescimento indeterminado em superar os níveis de desfolha. HAILE et al. (1998), em estudo com uma cultivar de soja com hábito de crescimento indeterminado, em níveis de desfolha no florescimento pleno, relatam que as plantas em ano com precipitação dentro da normalidade compensam a perda da área foliar pela retomada do crescimento, atrasando a senescência das folhas e elevando a capacidade de interceptação de luz do dossel com desfolha, onde os níveis de desfolhamento não resultaram em efeitos negativos sobre a produtividade.

Os resultados expressos por este trabaIho estão de acordo com os trabalhos conduzidos por REICHERT \& COSTA (2003), PARCIANELLO et al. (2004), PELUZIO et al. (2004) e BAHRY et al. (2013), em que não se constataram diferenças significativas na produtividade quando a desfolha é realizada nos estádios vegetativos. Os três primeiros autores mencionados reportam, ainda, que há maiores decréscimos no rendimento quando ocorre perda da área foliar nos estádios reprodutivos, principalmente na fase de formação e enchimento dos legumes. Isso se deve ao fato de as folhas encerrarem seu crescimento na fase reprodutiva, sendo o potencial de recuperação bastante limitado, comparado com períodos anteriores. Exceção às cultivares de hábito de crescimento indeterminado, que mantêm o crescimento vegetativo concomitante à fase reprodutiva, podendo minimizar os impactos devido à desfolha precoce na fase reprodutiva (THOMAS \& COSTA, 2010). Em trabalho conduzido por SOUZA et al. (2013) com desfolha em trigo nos estádios vegetativos, foram evidenciadas reduções significativas de $18,33 \%$ no rendimento de grãos e $1,82 \%$ no peso hectolítrico da cultura. Desta forma, presume-se que oleaginosas e cereais respondem de forma contrastante para o estresse por desfolha.

No caso em particular da soja, as plantas apresentam capacidade de se recuperar à desfolha sofrida, dependendo da intensidade e da fase em que ocorre. A área foliar restante, após 0 ataque de desfolhadores, simulados aqui pela desfolha artificial, é, se a desfolha não for drástica, capaz de realizar fotossíntese suficiente para garantir a produção de energia, que será revertida em boa nutrição para a planta, fazendo com que a produção final por área seja semeIhante (BUENO et al., 2010). Lembrando que, além do processo fotossintético, a planta também apresenta remobilização de reservas e que podem contribuir para o suprimento, pelo menos temporário, dos órgãos-dreno.

\section{Conclusões}

O índice de clorofila em plantas de soja não é afetado pela desfolha na fase vegetativa.

$O$ desfolhamento nos estádios vegetativos reduz até $50,3 \%$ o número de flores totais e $22,2 \%$ o número de legumes em formação, porém tais reduções são compensadas pelo aumento na produção de flores nos estádios subsequentes: fixação e enchimento destes legumes.

Os níveis de desfolhamento não influenciam no número de legumes totais e não prejudicam o rendimento de grãos da cultura da soja.

\section{Referências}

BAHRY, C. A.; DANTAS, E. L.; VENSKE, E.; NARDINO, M. ; ZIMMER, P. D. ; SOUZA, V. Q. ; CARON, B. O. Efeito da desfolha na fase vegetativa em alguns caracteres agronômicos da cultivar de soja BMX Potência RR. Revista de Agricultura, Piracicaba, v.88, n.3, p.179-184, 2013.

BAHRY, C. A.; VENSKE, E.; NARDINO, M.; ZIMMER, P. D.; SOUZA, V. Q.; CARON, B. O. Desempenho agronômico da soja em função da desfolha em diferentes estádios vegetativos. Tecnologia \& Ciência Agropecuária, Paraíba, v.7, p.19-24, 2013.

BUENO, A. F.; BATISTELA, M.; MOSCARDI, F.; BUENO, R. C. O. F.; NISHIKAWA, M.; HIDALGO, G.; SILVA, L.; GARCIA, A.; CORBO, E.; SILVA, R. B. Níveis de desfolha tolerados na cultura da soja sem a ocorrência de prejuízos à produtividade. Londrina: Embrapa CNPSO, 2010. 12p. (Circular Técnica, 79). 
CAVINESS, C. E.; THOMAS, J. D. Yield reduction from defoliation of irrigated and non-irrigated soybeans. Agronomy Journal, Madison, v.72, n.6, p.977-980, 1980.

DIOGO A. M.; SEDIYAMA, T.; ROCHA, V. S.; SEDIYAMA, C. S. Influência da remoção de folhas em vários estádios de desenvolvimento, na produção de grãos e em outras características agronômicas da soja (Glycine max (L). Merril). Revista Ceres, Viçosa, MG, v.44, n.253, p.272-285, 1997.

FEHR, W. R.; CAVINESS, C. E. Stages of soybean development. Ames: lowa State University of Science and Technology, Agriculture and Home Economics Experiment Station, Cooperative Extension Service, 1977. 11p. (Special Report, 80).

FENDRICH, R. Chuva e produtividade da soja na Fazenda experimental gralha azul da PUCPR. Revista Acadêmica: Ciências agrárias e ambientais, Curitiba, v.1, n.2, p.37- 46, 2003.

HAILE, F. J.; HIGLEY, L. G.; SPECHT, J. E. Soybean cultivars and insect defoliation: Yield loss and economic injury levels. Agronomy Journal, Madison, v.90, n.3, p.344-352,1998.

JIANG, A. C. D.; GAOB, H. Y.; ZOUB, Q.; JIANGA, G. M.; LIA, L. H. Leaf orientation, photorespiration and xanthophyll cycle protect Young soybean leaves against high irradiance in field. Environmental and Experimental Botany, Elmsford, p.1-10, 2004.

MORAN, R.; PORATH, D. Chlorophyll determination in intact Tissues using $N, N$ Dimethylformamide. Plant Physiology. Minneapolis, v.65, 478-479, 1980.

NAVARRO JÚNIOR, H. M.; COSTA, J. A. Expressão do potencial de rendimento de cultivares de soja. Pesquisa Agropecuária Brasileira, Brasília, v.37, n.3, p.275-279, mar. 2002.

NOGUEIRA, P. D. M.; JÚNIOR, D. G. S.; RAGAGNIN, V. A. Clorofila foliar e nodulação em soja adubada com nitrogênio em cobertura. Global Science and Technology, Asheville, v.3, n.2, 2010.

PARCIANELLO, G.; COSTA, J. A.; PIRES, J. L. F.; RAMBO, L.; SAGGIN, K. Tolerância da soja ao desfolhamento afetada pela redução do espaçamento entre fileiras. Ciência Rural, Santa Maria, v.34, n.2, p.357-364, mar-abr, 2004.

PELUZIO, J. M.; BARROS, H. B.; BRITO, E. L.; SANTOS, M. M.; SILVA, R. R. Efeitos sobre a soja do desfolhamento em diferentes estádios fenológicos. Revista Ceres, v.51, n.297, p.575585, 2004.
PEREIRA, C. R. Análise do crescimento e desenvolvimento da cultura de soja sob diferentes condições ambientais. 2002. 282f. Tese (Doutorado em Engenharia Agrícola)-Universidade Federal de Viçosa, 2002.

REICHERT, J.; L. COSTA, E. C. Desfolhamentos contínuos e seqüenciais simulando danos de pragas sobre a cultivar de soja BRS 137. Ciência Rural, Santa Maria, v.33 n.1, 2003.

RIBEIRO, A. L. P.; COSTA, E. C. Desfolhamento em estádios de desenvolvimento da soja, cultivar BR 16, no rendimento de grãos. Ciência Rural, Santa Maria, v.30, n.5, p.767-771, 2000.

SHARMA, K. P.; DYBING, C. D.; LAY, C. Soybean flower abortion: genetics and impact of selection on seed yield. Crop Science, Madison, v.30, n.5, p.1017-1022, Sept./Oct. 1990.

SHOFFEL, E. R.; VOLPE, C. A. Eficiência de conversão da radiação fotossinteticamente ativa interceptada pela soja para produção de fitomassa. Revista Brasileira de Agrometeorologia, Santa Maria, n.2, v.9, p.241-249, 2001

SOUZA, V. Q.; NARDINO, M.; BONATO, G. O.; BAHRY, C. A.; CARON, B. O.; ZIMMER, P. D.; SCHIMIDT, D. Desfolha em diferentes estádios fenológicos sobre características agronômicas em trigo. Bioscience Journal, Uberlândia, v.29, n.6, 2013.

TAIZ, L; ZEIGER, E. Fisiologia vegetal. 4.ed. São Paulo: Editora Artmed, 2009. 819p.

THOMAS, A. L.; COSTA, J. A. Desenvolvimento da planta de soja e o potencial de rendimento de grãos. In: THOMAS, A. L.; COSTA, J. A. (Org.). Soja: manejo para alta produtividade de grãos. Porto Alegre: Evangraf, 2010. p.13-34. 243p.

THORNE, J. H.; KOLLER, H. R. Influence of assimilate demand on photosynthesis, diffusive resistances, translocation, and carbohydrate levels of soybean leaves. Plant Physiology, Minneapolis, v.54, p.201-207, 1974.

VENTIMIGLIA, L. A.; COSTA, J. A.; THOMAS, A. L.; PIRES, J. L. F. Potencial de rendimento da soja em razão da disponibilidade de fósforo no solo e dos espaçamentos. Pesquisa Agropecuária Brasileira, Brasília, v.34, n.2, p.195-199, fev. 1999.

WIEBOLD, W. J. Rescue of soybean flowers destined to abscise. Agronomy Journal, Madison, v. 82, n.1 p.85-88, jan./fev. 1990.

WIEBOLD, W. J.; PANCIERA, M. T. Vasculature of soybean racemes with altered intraraceme competition. Crop Science, Madison, v.30, n.5, p.1089-1093, Sept./Oct. 1990. 